\title{
PREOPERATIVE CLINICAL AND RADIOLOGICAL ASSESSMENT IN PREDICTING DIFFICULT LAPAROSCOPIC CHOLECYSTECTOMY- A STUDY AT GOVERNMENT GENERAL HOSPITAL, GUNTUR
}

\author{
Mudavatu Bhagavan Naik1, Meghavathu Govindu Naik2, Nishanth Sadhanala ${ }^{3}$
}

1 Professor, Department of Surgery, Guntur Medical College and Government General Hospital, Guntur, Andhra Pradesh, India. ${ }^{2}$ Assistant Professor, Department of Surgery, Guntur Medical College and Government General Hospital, Guntur, Andhra Pradesh, India. 3Junior Resident, Department of Surgery, Guntur Medical College and Government General Hospital, Guntur, Andhra Pradesh, India.

\section{BACKGROUND}

ABSTRACT

Since its inception, Laparoscopic cholecystectomy has become the gold standard for gall bladder surgery and is one of the most commonly performed laparoscopic surgeries. Despite advances, at times it becomes difficult and may require conversion to open technique.

\section{MATERIALS AND METHODS}

The present study evaluated 86 patients undergoing laparoscopic cholecystectomy in Government General Hospital during the period from 2016 to 2017 fulfilling the inclusion and exclusion criteria. Standard four port Laparoscopic Cholecystectomy was performed in all cases after taking written consent and collecting required information. The outcome of each case was noted. Analysis was done by Chi-square test, Fisher exact test, t-test and Univariate analysis using BioStats software.

\section{RESULTS}

A total number of 86 patients underwent laparoscopic cholecystectomy. Operative difficulty, either an identified bile duct injury or cases requiring conversion to open technique was observed in 6 cases. Patients with history of recent attacks in the past six months, increased total leucocyte counts and a thick gall bladder wall required conversion significantly more than others.

\section{CONCLUSION}

Present study identified history of recent attacks, increased total leucocyte counts and a thickened gall bladder wall as the most important factors in conversion.

\section{KEY WORDS}

Laparoscopic Cholecystectomy, Pre-Operative, Prediction, Difficult Surgery.

HOW TO CITE THIS ARTICLE: Naik MB, Naik MG, Sadhanala N. Preoperative clinical and radiological assessment in predicting difficult laparoscopic cholecystectomy- a study at Government General Hospital, Guntur. J. Evolution Med. Dent. Sci. 2018;7(22): 2694-2697, DOI: $10.14260 /$ jemds/2018/607

\section{BACKGROUND}

Diseases of the gallbladder commonly manifests, as gallstones remain one of the major causes of morbidity and mortality throughout the world. The prevalence of cholelithiasis in India is more in females compared to males.[1] The prevalence of cholelithiasis had different regional distributions in India with comparatively more in Northern part of the country.[1]

Within a short span of merely two decades since its introduction, Laparoscopic cholecystectomy has become widely accepted as the procedure of choice for symptomatic gall bladder disease. It has become one of the most commonly performed operations with around $80 \%$ of cholecystectomies performed using laparoscopic method.2,3,4

It has many advantages such as small incision, early recovery, minimal post-operative pain, shorter hospital stay and less pain compared with open cholecystectomy.

'Financial or Other Competing Interest': None.

Submission 20-03-2018, Peer Review 18-04-2018,

Acceptance 25-04-2018, Published 28-05-2018.

Corresponding Author:

Dr. Meghavathu Govindu Naik,

Door no: 85-6-422, 4th Lane

Kodandaramaiah Nagar,

Lalapuram, Chuttugunta

Guntur-522004, Andhra Pradesh, India.

E-mail:mgnaik009@yahoo.in

DOI: $10.14260 /$ jemds $/ 2018 / 607$

\section{(c) $($ ) $९$}

Although, safe and uneventful mostly, but laparoscopic cholecystectomy can be difficult, especially with technical challenge in viewing or dense adhesions between gall bladder and adjoining structures. Approximately, $2 \%$ to $15 \%$ of patients may require conversion to open surgery for various reasons such as patients with long-standing disease and previous history of cholecystitis and few others.

Ultrasound findings such as number of stones, gall bladder wall thickness, contracted gall bladder may prove to be potential operative difficulties.5,6

The main objective was to analyse specific variables and their role in the conversion of laparoscopic cholecystectomy to open cholecystectomy.

\section{MATERIALS AND METHODS}

The cases for the study were taken from patients admitted to Government General Hospital, Guntur during 2016 and 2017.

\section{Study Design}

Prospective observational study.

\section{Inclusion Criteria}

All patients undergoing laparoscopic cholecystectomy.

\section{Exclusion Criteria}

Pregnant women, patients with CBD stones were excluded from the study. 
A detailed history was taken regarding name, age, sex and clinical and radiological variables and operative data were collected.

\section{Examination}

All cases were examined thoroughly, and the findings were recorded. In all cases complete general physical examination, local examination and systemic examination was done. All the cases were examined by inspection, palpation, percussion and auscultation.

\section{Investigations}

We undertook the following investigations as required:

Haematological- Hb\%, TLC, DC, ESR, Biochemical- RBS, RFT, LFT.

Radiological- Ultrasound abdomen and Chest x-ray.

After complete workup, clinical diagnosis was ascertained, and patients underwent laparoscopic cholecystectomy.

All patients were informed of the risks and benefits of the procedure and also explained about the risk for conversion to open procedure and consent was taken. Senior surgeons operated all cases. All cases were done using the standard four-port technique. Conversion to open procedure was recorded. All patients received standard and similar pre-, peri- and post-operative care.

\section{Statistical Methods Applied \\ Binary Outcomes}

The Chi-square test and Fisher exact tests are used to determine whether certain groups have significantly different proportions of a particular characteristic.

Unpaired t-test was used for numerical data and to determine whether there is a significant difference between the mean values of the two populations.

$P$ value of $<0.05$ was considered to be significant.

All the statistical methods were carried out through the BioStats calculator for IOS4 and Microsoft Excel for Windows10.

\section{RESULTS}

During two years of study period, a total of 86 cases underwent laparoscopic cholecystectomy after thorough clinical evaluation and workup.

Conversion to laparotomy was required in 6 cases (6.97\%):
- 3 were because of dense adhesions.

- 1 was because of difficulty in delineating the anatomy.

- 2 were because of difficulty handling the gall bladder.

Mean age was 48.5 years (range 26 - 76). 49 were women, 36 were men.

The mean age in non-converted cases was not statistically different from the conversion group ( $p>0.05)$ and the conversion rate in males was also not significantly different from that in females.

With regards to BMI, the difference between the two groups was not statistically significant.

Of the 86 patients, 32 patients had history of acute cholecystitis attacks and the rest had history of dyspeptic symptoms. Patients with history of an acute attack in the past six months had a significantly higher conversion rate $(p=0.01)$. It was found that the conversion rate was higher in patients with $>3$ attacks.

In this study of 86 patients, there were 9 patients with raised TLC. 3 patients with normal values underwent conversion as compared to 3 patients with raised counts. TLCs were found to be statistically significant for risk of conversion.

No statistically significant difference was seen between contracted gall bladder and non-contracted with risk of conversion.

A total of 73 patients had normal wall thickness with a conversion rate of $2.73 \%$ ( 2 cases) as compared to $30.76 \%$ ( 4 out of 13 cases) with thick gall bladder wall. Thickened gall bladder walls were found to be statistically significant for risk of conversion.

A single stone was present in 22 patients, while 64 patients had more than one stone and the difference between the two groups was not statistically significant.

With a p-value of $<0.005$, gall bladder thickness was found to be the most significant variable. In an effort to narrow down the factors that were more important, we analysed the four significant variables. Stepwise logistic regression to find the independent risk factors showed only wall thickness to be statistically significant. Then step-wise logistic regression was performed deleting one nonsignificant variable at a time. Final logistic regression matrix showed that only recent history of attack, more number of attacks and wall thickness were statistically significant.

\begin{tabular}{|c|c|c|c|}
\hline Variable & Converted & Non-Converted & P-value \\
\hline Age (Mean) & $48.92 \pm 11.92$ & $47.75 \pm 14$ & $>0.05$ \\
\hline $\begin{array}{c}\text { Sex } \\
\text { Male } \\
\text { Female }\end{array}$ & $\begin{array}{l}2 \\
4\end{array}$ & $\begin{array}{l}35 \\
45\end{array}$ & 1 \\
\hline $\begin{array}{c}\text { BMI } \\
\text { High } \\
\text { Low }\end{array}$ & $\begin{array}{l}3 \\
3 \\
\end{array}$ & $\begin{array}{l}23 \\
57 \\
\end{array}$ & 0.66 \\
\hline Recent history of attack & 05 & 27 & 0.01 \\
\hline $\begin{array}{l}\text { Number of Attacks } \\
\text { Up to } 3 \text { previous attacks } \\
>3 \text { previous attacks }\end{array}$ & $\begin{array}{l}3 \\
3\end{array}$ & $\begin{array}{c}76 \\
4\end{array}$ & $<0.05$ \\
\hline Raised total leucocyte count & 3 & 6 & 0.01 \\
\hline Gall bladder contracted & 2 & 11 & $>0.05$ \\
\hline Thickened gall bladder wall & 4 & 9 & $<0.005$ \\
\hline $\begin{array}{l}\text { Number of Stones } \\
\text { Single stone } \\
\text { Multiple stones }\end{array}$ & $\begin{array}{l}3 \\
3\end{array}$ & $\begin{array}{l}19 \\
61\end{array}$ & 0.211 \\
\hline
\end{tabular}




\section{DISCUSSION}

The present study, which has been done in a tertiary level hospital in Guntur showed a total of 86 patients who underwent laparoscopic cholecystectomy in a span of two years from 2016 - 2017.

Mean age of the study population was 48.5 years with female preponderance. Similar observations were seen in study by Ravindra Nidoni et al (2015), ${ }^{7}$ where the mean age was 44.1 years and male: female ratio was $1: 1.76$.

Another study by Nikhil Khandelwal et al (2017) ${ }^{8}$ found that majority (60\%) were aged more than 45 years of age and $92 \%$ of the cases were females.

\section{Conversion to Open Cholecystectomy}

In the present study, conversion to open surgery was required in 6 cases with a conversion rate of $6.97 \%$.

This is comparable with other studies, Arun PS et al (5.8\%), ${ }^{9}$ Gupta N et al (4.3\%), Ravindra Nidoni et al (5.55\%), ${ }^{7}$ Vijay Kassa and S. Nimbalkar (3.3\%).10

Among the 6 cases, 3 were because of dense adhesions, 1 case was because of difficulty in delineating the anatomy and 2 were because of difficulty handling the gall bladder.

In a study by Vijay Kassa and S. Nimbalkar (2017), ${ }^{10}$ two cases converted to open because they were difficult to dissect and severe bleeding.

\section{Factors associated with Conversion}

Statistical association between converted and non-converted cases in the present study found that recent history of attack, previous history of more than 3 attacks, raised leucocyte count and thickened gall bladder had a significant association with conversion with p-value being less than 0.05 .

Age, sex of the patients, higher body mass index (BMI), contracted gall bladder and number of stones had no statistical association with conversion.

In a similar kind of study by Gupta AK et al (2018), he observed that symptom duration of more than a year, history of acute cholecystitis and higher BMI had a significant association with conversion. Age, gender, past abdominal surgery, thickened gall bladder, small contracted gall bladder and single large stone had no significance in conversion.

Another study by Arun PS et al (2017) found that patients who had multiple attacks of acute cholecystitis had higher chances of difficult laparoscopic cholecystectomy and conversion. Thickened gall bladder was a potential risk factor for difficult laparoscopic cholecystectomy and impacted gall stone had no impact.

In contrast to present study findings, in most of the studies on patients with advanced age ( $>65$ years), an increase in complication and conversion rate is reported and age is recognised as a risk factor for conversion.11,12 Liu et al ${ }^{13}$ in their study found that age more than 65 years predicted conversion. Similarly, Kama et al ${ }^{14}$ found age $>60$ years as a risk factor for conversion.

In the conversion group mean BMI of male was 30.4 and female was 29.3 , both being normal. In the study by Liu et al, ${ }^{13}$ highest rate of conversion was seen in obese patients (25\%).

Sanabria et $\mathrm{al}^{6}$ found in their study of 628 patients that patients with multiple attacks (ten or more) were significantly associated with conversion, but in our study, we found increased conversion with a number of attacks more than four. The number of previous attacks was found to be a very significant factor in our study.

Limitation of the study was it did not include any cases of acute cholecystitis, experienced surgeons carried out all surgeries and no in-depth study of cause of conversion was done.

\section{CONCLUSION}

According to present study analysis, patients with more number of attacks, recent history of attack and a thick gall bladder wall required conversion significantly more than others. When these three variables were again analysed, it was found that 5 out of 6 converted cases had high values of at least two of these three variables. We believe that none of these factors contraindicates laparoscopic cholecystectomy. However, they are good predictors of conversion to open cholecystectomy.

\section{REFERENCES}

[1] Bansal A, Akhtar M, Bansal AK. A clinical study: prevalence and management of cholelithiasis. Int Surg J 2014;1(3):134-9.

[2] Das S. Biliary system. In: Das S, editor. A concise textbook of surgery. $6^{\text {th }}$ edn. Kolkata: S.R Das Publishers 2010.

[3] Zinner MJ, Ashley SW. Maingot's abdominal operations. $12^{\text {th }}$ edn. China: The McGraw-Hill Companies 2013.

[4] Gupta AK, Shiwach N, Gupta S, et al. Predicting difficult laparoscopic cholecystectomy. Int Surg J 2018;5(3):1094-9.

[5] Alponat A, Kum CK, Koh BC, et al. Predictive factors for conversion of laparoscopic cholecystectomy. World J Surg 1997;21(6):629-33.

[6] Sanabria JR, Gallinger S, Croxford R, et al. Risk factors in elective laparoscopic cholecystectomy for conversion to open cholecystectomy. J Am Coll Surg 1994;179(6):696-704.

[7] Nidoni R, Udachan TV, Sasnur P, et al. Predicting diffiult laparoscopic cholecystectomy based on clinicoradiological assessment. J Clin Diag Res 2015;9(12):PC09-12.

[8] Khandelwal N, Salim M, Gandhi A. Predicting difficult laparoscopic cholecystectomy based on clinicoradiological parameters. Sch J App Med Sci 2017;5(4B):1343-7.

[9] Arun PS, Rathnakar SK, Nagaraja AL. A study on clinical and radiological factors for predicting difficult laparoscopic cholecystectomy preoperatively. Int Surg J 2017;4(9):3015-8.

[10] Kassa V, Nimbalkar S. Clinico-radiological assessment for prediction of difficult laparoscopic cholecystectomy. MedPulse - International Medical Journal 2017;4(2):268-71.

[11] Fried GM, Barkun JS, Sigman HH, et al. Factors determining conversion to laparotomy in patients undergoing laparoscopic cholecystectomy. Am J Surg 1994;167(1):35-41.

[12] Jansen S, Jorgensen J, Caplehorn J, et al. Preoperative ultrasound to predict conversions in laproscopic cholecystectomy. Surg Laparosc Endosc 1997;7(2):121-3. 
[13] Liu CL, Fan ST, Lai EC, et al. Factors affecting conversion of laparoscopic cholecystectomy to open surgery. Arch Surg 1996;131(1):98-101.
[14] Kama NA, Kologlu M, Doganay M, et al. A risk score for conversion from laparoscopic to open cholecystectomy. Am J Surg 2001;181(6):520-5. 